\title{
Microbially Mediated Immobilization of Contaminants Through In Situ Biostimulation: Scale up of EMSP project 55267
}

June 28, 2002

Philip M. Jardine

Oak Ridge National Laboratory

P.O. Box 2008

Oak Ridge, TN 37831-67038

865-574-8058

jardinepm@ornl.gov

Scott E. Fendorf

Stanford University

Dept. Geological and Environ. Sci.

Palo Alto, CA 94305

650-723-5238

fendorf@stanford.edu
Scott C. Brooks

Oak Ridge National Laboratory

P.O. Box 2008

Oak Ridge, TN 37831-6038

865-574-6398

brookssc@ornl.gov

Students / post grads: 1 undergraduate student

2 post-doctoral

\section{Purpose and Objectives}

The overall goal of the proposed research is to provide an improved understanding and predictive capability of the mechanisms that allow metal-reducing bacteria to be effective in the bioremediation of redox sensitive toxic metals and radionuclides. The study is motivated by the likelihood that subsurface metal-reducing bacteria can be stimulated to effectively alter the redox state of contaminants so that they are immobilized in situ for long time periods. The work described in this proposal will advance the technological and scientific needs associated with the long-term management of the enormous inground inventories of $\mathrm{Cr}, \mathrm{U}, \mathrm{Tc}$, and Co present at numerous DOE installations throughout the country. The objectives of our project are to (1) develop an improved understanding and predictive capability of the rates and mechanisms controlling microbially mediated reduction of toxic metals and radionuclides in heterogeneous field settings, (2) quantify the impacts of hydrological and geochemical processes on the effectiveness of indigenous microorganisms to transform and immobilize radionuclides and metals in situ, (3) provide an improved understanding of the importance of microbial consortia interactions in the bacterial immobilization of radionuclides and toxic metals, and (4) determine intrinsic bioreduction rate parameters to improve our generic predictive capability of in situ microbially mediated metal reduction.

This report summarizes $1.5 \mathrm{y}$ of research for a $3 \mathrm{y}$ project. 


\section{Progress and Relevance to EM Needs}

Our approach involves a multiscale experimental and numerical endeavor that uses (1) a well-characterized, highly instrumented field facility for assessing biostimulation remedial strategies involving Co(III)EDTA;, (2) multiple tracer techniques designed to delineate the influence of coupled hydrological, geochemical, and microbial processes, (3) a novel microarray-based genomic technology for rapidly characterizing shifts in microbial community structure and activity, (4) sophisticated surface analysis techniques (x-ray absorption spectroscopy) for quantifying the distribution and chemical environment of the immobilized contaminants, and (5) next-generation, highperformance hydrobiogeochemistry modeling to assist the design and performance assessment of the proposed field scale experiment.

Previous results in our group have demonstrated the sustained microbial reduction of ${ }^{60} \mathrm{Co}$ (III)EDTA to ${ }^{60} \mathrm{Co}$ (II)EDTA under dynamic flow conditions (Brooks et al., 1999). The net reduction of the ${ }^{60} \mathrm{Co}(\mathrm{III}) \mathrm{EDTA}$ dominated the fate and transport of this contaminant, even in the presence of strong mineral oxidants commonly found in the subsurface (e.g. Mn- and Fe-oxides). The environmental implications of these findings are pronounced since ${ }^{60} \mathrm{Co}(\mathrm{III}) \mathrm{EDTA}$ is extremely stable and soluble, and this enhances its persistence and transport in subsurface environments. By discovering a way to keep the bacteria healthy and growing, we were able to effectively stabilize ${ }^{60} \mathrm{Co}$ (II)EDTA in a flowing subsurface system. This is advantageous from a remedial perspective since ${ }^{60} \mathrm{Co}$ (II)EDTA is a weaker complex than ${ }^{60} \mathrm{Co}$ (III)EDTA, and therefore easier to decouple and remediate. These research findings coupled with our current progress described below, are providing new and important information on how to successfully implement metal bioreduction strategy at the field scale.

$\underline{\text { Research progress to date includes: }}$

\section{Microbiology}

- Microbial community dynamics of the groundwater from the field site have been characterized for direct counts (AODC), aerobic heterotrophs, anaerobic heterotrophs, fermenters ( $\mathrm{SO}_{4}{ }^{2-}$ reducers, methanogens, $\mathrm{H}_{2}$ utilizers), nitrate reducers, $\mathrm{Co}$ (III)EDTA reducers, $\mathrm{Fe}(\mathrm{III})$ reducers, $\mathrm{Mn}(\mathrm{IV})$ reducers, $\mathrm{SO}_{4}{ }^{2-}$ reducers, methanogens, and $\mathrm{Fe}(\mathrm{II})$ oxidizers.

- We have isolated and purified numerous metal-reducing and denitrifying bacteria from the site groundwater at various spatial locations. Over 35 metal reducing and 60 denitrifying isolates have been uniquely fingerprinted and their 16s rDNA fragments have been successfully PCR amplified, using FD1 and 1540r as primers, in an effort to determine the phylogeny affinity of the isolates. Each of the metal-reducing isolates from the field-site groundwater have been screened for Fe-citrate and $\mathrm{Co}(\mathrm{III}) \mathrm{EDT}$ A reduction. 
- Numerous groundwater nutrient and electron donor amendment strategies were investigated in the laboratory in an effort to determine the optimal nutrient regime necessary to simulate bacteria involved in metal reduction. Various concentrations of nutrients such as ammonium and phosphate, and electron donor such as ethanol, methanol, lactate, acetate, and pyruvate, were used to stimulate growth. Each scenario was tested in time-course studies that investigated the kinetics of Co(III)EDTA reduction. Scenarios resulting in biostimulation produced reduction rates with time scales of hours to days which is sufficiently rapid to ensure that efficient toxic metal reduction could occur in situ within our fractured system which has rapidly moving groundwater

- Novel DNA microarray chips have been constructed which contain several hundred genes and they are ready to be used in for the rapid analysis of microbial community structure and activity during the biostimulation experiment. Using the microarray technology we will be able to understand how contaminants and spatial isolation impact microbial community structure and activities in natural environments.

- Microarray results have been cross-correlated with conventional molecular detection methods (e.g. quantitative PCR), thus providing validation for quantitative assessment by microarray hybridization.

\section{Field-Scale setup}

- Field site geochemical dynamics including temperature, $\mathrm{pH}$, Eh, dissolved $\mathrm{O}_{2}$, $\mathrm{NO}_{3} / \mathrm{NO}_{2}, \mathrm{Fe}(\mathrm{III}) / \mathrm{Fe}(\mathrm{II}), \mathrm{SO}_{4}{ }^{2-} / \mathrm{S}^{2-}, \mathrm{CO}_{2} / \mathrm{CH}_{4}, \mathrm{Cl}^{-}$, major cations and anions, $\mathrm{TOC}$, and alkalinity have been quantified as a function of time in both the fracture and matrix regime.

- Field site hydrologic and geochemical processes have compiled and documented through publication and the design of the field scale contaminant injection and biostimulation experiment have been initiated.

- Permitting for the (1) tracer injection, (2) additional well installation, (3) and a variety of legal issues has been completed, agreed upon, and signed by the State of Tennessee and local regulators and land owners.

- Well field enhancement is nearly complete with the installation of approximately 20 new multilevel sampling and nutrient/electron donor injection wells.

- An extensive supply of Co(III)EDTA solid phase has been produced and purified in our laboratory and it is ready for use in our field biostimulation experiments that are planned to be initiated within the next month or two.

\section{Modeling}


- Solute transport parameters and geochemical rate coefficients were obtained using laboratory solute transport data and a public domain hydrobiogeochemical code HBGC123D developed within our group, coupled with a two parameter estimation technique. These parameters are being used to help design the field biostimulation experiment.

\section{Implications:}

The experimental and numerical results from this research will provide knowledge and information in previously unexplored areas of in situ biostimulation for metal and radionuclide immobilization to support EM's mission of long-term isolation and in situ remediation of contaminated environments. By unraveling the fundamental mechanisms controlling the microbially mediated reduction and immobilization of contaminants in situ, we provide an enhanced opportunity for successfully implementing biostimulation strategies at numerous DOE installations that are plagued with legacy waste.

\section{Publications:}

\section{Peer-reviewed}

Jardine, P.M., G.V. Wilson, R.J. Luxmoore, and J.P. Gwo. 2001. Conceptual Model of Vadose-Zone Transport in Fractured Weathered Shales. (In) Conceptual Models of Flow and Transport in the Fractured Vadose Zone. U.S. National Committee for Rock Mechanics. National Research Council. National Academy Press, Washington D.C. p. 87-114.

Gwo, J.P., E.F. D’Azevedo, H. Frenzel, M. A. Mayes, G.T. Yeh, P.M. Jardine, K.M. Salvage, and F.M. Hoffman. 2001. HBGC123D: A high performance computer model of coupled hydrological and biogeochemical processes. Computers and Geosciences. 27:12311242.

Bostick, B.C., M.O. Barnett, P.M. Jardine, S.C. Brooks, S.E. Fendorf. 2002. Uranyl surface species formed on subsurface media from DOE facilities. Soil Sci. Soc. Am. J. 66:99-108.

Jardine, P.M., T.L. Mehlhorn, I.L. Larsen, W.B. Bailey, S.C. Brooks, Y. Roh, and J.P. Gwo. 2002. Influence of hydrological and geochemical processes on the transport of chelatedmetals and chromate in fractured shale bedrock. J. Contamin. Hydrol. 55:137-159.

Barnett, M.O., P.M. Jardine, and S.C. Brooks. 2002. U(VI) adsorption to heterogeneous subsurface media: Application of a surface complexation model. Environ. Sci. Technol. 36:937-942.

Jardine, P.M. 2002 Fate and Transport of Radionuclides. (In) Encyclopedia of Soil Science. R. Lal (ed.) Marcel Dekker, Inc. (in press).

Jardine, P.M. 2002. Soil Chemistry and Mineralogy: Kinetic Models (In) Encyclopedia of Soils in the Environment. D. Hillel (ed.) Academic Press, London, UK (submitted). 
Gwo, J.P. and P.M. Jardine. 2002. Determining hydraulic and advective mass transfer parameters of a fractured waste disposal site: a two pore region model. Ground Water (submitted).

\section{Abstracts and presentations}

Jardine, P.M., T.L. Mehlhorn, I.L. Larsen. 2001. Quantifying time-dependent physical and chemical processes that influence the migration of chelated radionuclides in fractured shale. Fractured Rock 2001. March 26-28, 2001, Toronto, Ontario, Canada.

Jardine, P.M., M.A. Mayes, T.L. Mehlhorn, and S.C. Brooks. 2001. Reactive transport of chelated radionuclides through weathered shale saprolite: Observations from lab and field experimentation. Goldschmidt 2001 conference. May 20-24, Hot Springs, VA.

Jardine, P.M., M.A. Mayes, T.L. Mehlhorn, S.C. Brooks, and S.E. Fendorf. 2001. Influence of hydrological and geochemical processes on reactive contaminant transport in fractured subsurface media. Sixth International Conference on the Biogeochemistry of Trace Elements. July 29- August 2, Guelph, Ontario, Canada.

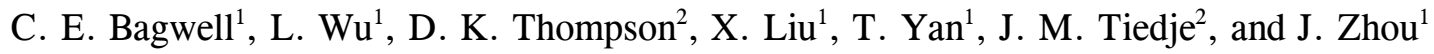
2002. Development and Performance of Functional Gene Microarrays for Sensitive Detection and Quantification of Microbial Community Structure and Function. 102nd General Meeting of the American Society for Microbiology.

\section{Research Transfer Information}

Research products from EMSP 73784 specifically provide knowledge and information in previously unexplored areas of in situ biostimulation for metal and radionuclide immobilization to support EM's mission of long-term isolation and in situ remediation of contaminated environments. Specific sites to benefit from this research are Oak Ridge's Y-12 facility where $\mathrm{U}$ and $\mathrm{NO}_{3}{ }^{-}$contaminants are widespread, and Hanford's 100 area where $\mathrm{Cr}(\mathrm{VI})$ resides adjacent the Columbia River.

Collaboration Information

Program Interaction: EMSP 73784 research members are directly involved in DOE's NABIR program that seeks innovative microbiological technologies to immobilize toxic metals and radionuclides in situ. The knowledge and the concepts developed in EMSP 73784 will allow larger scale biostimulation endeavors, such as those associated with NABIR, to be successfully implemented at contaminated sites that are plagued with legacy waste. 


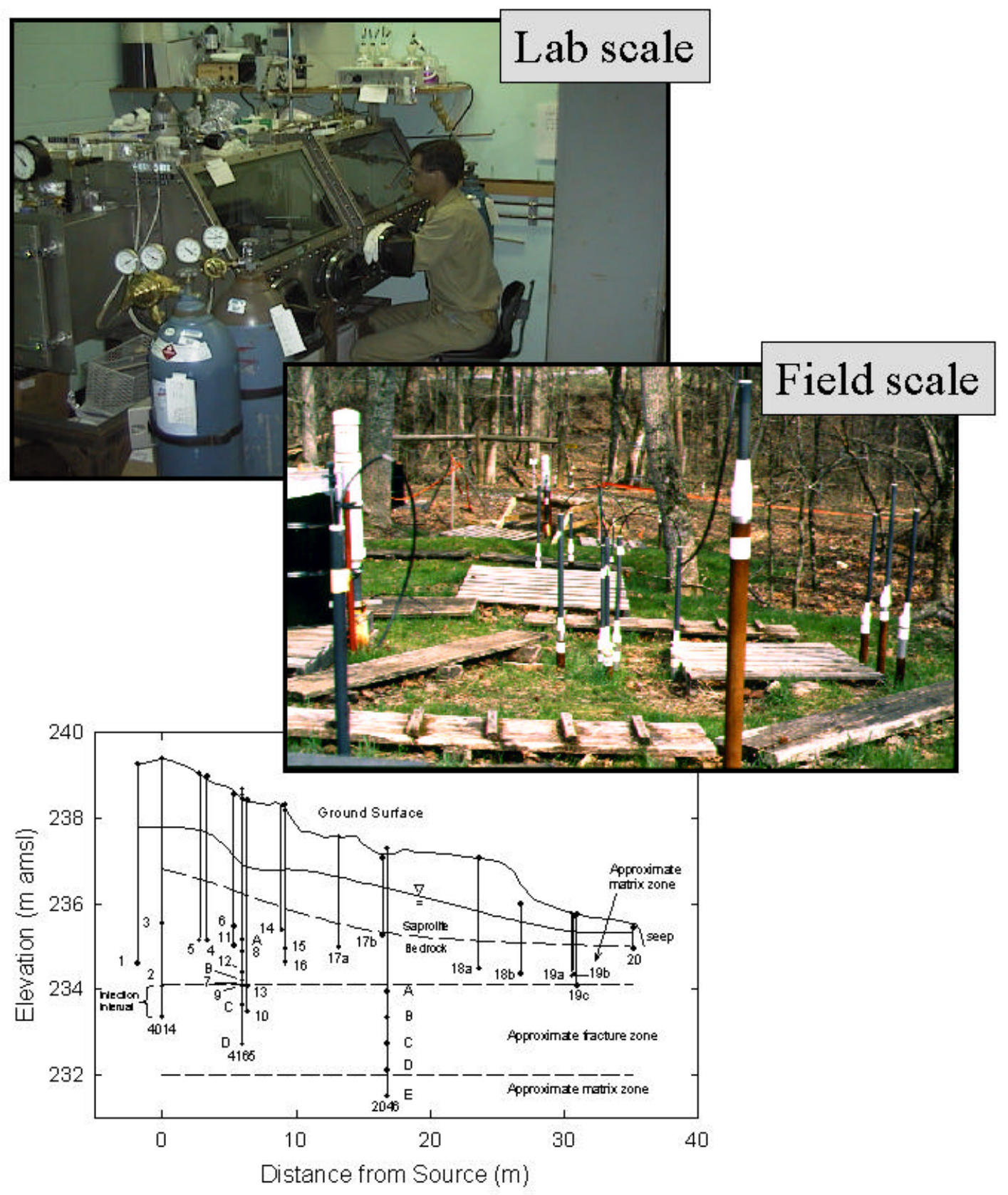

EMSP 73784: Integrating laboratory and field scale research to better understand the mechanisms controlling in situ metal and radionuclide immobilization through bioreduction. 